УДК 629.7

DOI: $10.54858 /$ dndia.2021-17-13

\author{
3.В. Хатунцева ${ }^{1}$ О.Ю. Маракулін ${ }^{1}$ \\ ${ }^{1}$ Державний науково-дослідний інститут авіачії, Київ
}

\title{
ІМІТАЦЙНА МОДЕЛЬ РОЗРАХУНКУ ЙМОВІРНОСТІ БОРТОВОГО НАВЕДЕННЯ НА ЦІЛЬ ІЗ ЗАСТОСУВАННЯМ МЕТОДУ ПАРАЛЕЛЬНОГО ЗБЛИЖЕННЯ
}

\begin{abstract}
Предмет досліджень полягає в розробиі алгоритму розрахунку ефективності атаки повітряноі малопомітної иілі методом паралельного зближення з урахуванням ракурсів опромінення цілі. Приведений приклад розрахунку ймовірності бортового наведення, де в якості иілі розглядається винищувач F-22, на який послідовно здійснюють атаку літаки F-22, F-35, F-18. Пояснені отримані результати. Метою досліджень є розробка науково-методичного апарату для обтрунтування на основі отриманих оцінок раціонального варіанта перспективного зразка бойової авіачійної техніки.
\end{abstract}

Ключові слова: метод паралельного наведення, упереджена точка зустрічі, ефективна площа розсіювання, ракурс опромінення.

\section{Вступ}

Провідні світові держави здійснюють переоснащення авіаційного парку на багатофункціональні літальні апарати (ЛА), проводять модернізацію ЛА, що знаходяться на озброєнні, здійснюють розробку і закупівлю керованого авіаційного озброєння нового покоління.

Головними особливостями таких ЛА є:

зниження демаскуючих ознак їх застосування у всіх діапазонах довжин хвиль (радіолокаційному, інфрачервоному, ультрафіолетовому, видимому, акустичному);

забезпечення підвищених маневрених характеристик за рахунок оснащення двигунів системами відхилення вектору тяги;

забезпечення значного бойового радіусу дії;

збільшення ефективності інтегрованого бортового радіоелектронного обладнання шляхом забезпечення:

повної ситуаційної інформованості (тактичної, навігаційної, радіоелектронної обстановки, технічного стану бортових систем);

можливості селекції і групування цілей за пріоритетами загроз;

автоматичного виявлення і подавлення радіоелектронних засобів противника;

автоматичного управління режимами випромінювання бортових засобів 3 метою забезпечення малої помітності літака;

розширення номенклатури застосування високоточних авіаційних засобів ураження різного призначення.

В Україні заходи щодо модернізації військової авіаційної техніки і продовження іiі ресурсів й строків служби принципово не забезпечують збереження військової авіації у перспективі, а лише на певний час запобігають скороченню чисельності й зниженню можливостей при вирішенні завдань існуючими авіаційними угрупованнями [1, с. 22].

Постановка завдання та його актуальність. Правильне рішення задачі оновлення парку тактичних літаків Збройних Сил України залежить від якості планування і реалізації заходів з розвитку озброєння та військової техніки збройних сил держави. У свою чергу ефективність указаних заходів визначається використанням розвинутого науково-методичного апарату і обгрунтуванням на основі отриманих оцінок раціонального варіанта перспективного зразка бойової авіаційної техніки.

При виборі раціонального варіанта багатофункціонального винищувача повинні враховуватися такі критерії ефективності як тактична перевага у повітряному бою (в тому числі наявність Stealth-технологій, що $\epsilon$ обов'язковим елементом бойових літаків п'ятого покоління, можливість одночасного обстрілу декількох цілей), ймовірність ураження при нанесенні високоточних ударів по наземних цілях (в тому числі одночасний обстріл декількох цілей), вартісні та ресурсні показники.

Малий рівень радіолокаційної помітності сучасного винищувача дозволяє діяти приховано; здійснювати пуск ракет середньої/великої дальності 3 гарантованої зони можливих пусків (в даному випадку - 3 області можливих атак), при потраплянні в яку ціль не має можливості уникнути ураження ракетою при будь-якому маневрі, включаючи маневр на відліт; забезпечувати можливість одночасного обстрілу декількох цілей. 
Ефективність атаки повітряних цілей винищувачем у вирішальній ступені визначається формуванням на борту методу наведення. 3 методів наведення на ціль, що використовуються в бортових системах винищувачів при застосуванні ракет середньої / великої дальності можна виділити такі, як крива атаки, паралельне зближення, комбінований метод самонаведення (поєднує позитивні якості методів пряме зближення і крива атаки), метод наведення на упереджену зону пуску та інші [2, с.145].

Аналіз попередніх досліджень. Загальна характеристика методів наведення літаків і ракет й траєкторного керування ними наведена в [2, с. $127 \ldots 135]$.

Згідно з [3, с.15] при наведенні винищувачів на рухомі повітряні цілі в залежності від умов застосування можуть використовуватися як прямі методи наведення, так i методи наведення в упереджену точку зустрічі.

Суть методу прямого наведення полягає в тому, що повздовжня вісь літака весь час повинна збігатися 3 напрямом на ціль (метод погоні) $[4$, c.13].

При наведенні винищувачів на рухомі повітряні цілі прямий метод забезпечує, загалом, політ літака криволінійною траєкторією (кривій погоні). Причиною викривлення $є$ той факт, що миттєвий напрям взаємного переміщення цілі і літака, що визначає напрям вектора відносної швидкості, в основному, не співпадає з напрямом на ціль [4, с.13].
Прямий метод наведення $\epsilon$ інваріантним до умов застосування, тобто закон формування курсового кута винищувача не змінюється при зміні висоти, дальності, швидкості зближення і напряму (ракурсу) перехоплення [3, с. 16].

Але найбільш значимим недоліком методу прямого наведення $\epsilon$ обмеження напряму перехоплення рухомих цілей тільки в задню півсферу [4, с.13].

Алгоритм траєкторного керування при наведенні в найвигіднішу упереджену точку зустрічі (УТЗ) також широко застосовується при наведенні винищувачів на повітряні цілі.

Важливою особливістю цього методу $\epsilon$ практична прямолінійність траєкторії винищувача при наведенні на неманевруючу ціль. Це $\epsilon$ реалізацією максимальної дальності дії радіоелектронної системи керування при мінімальних витратах енергії та часу наведення.

Одним з різновидів методу наведення в УТЗ є метод паралельного зближення, що приводиться в даній моделі [5, с. 325 ].

На рис. 1. наведена схема виникнення помилок наведення на ціль при паралельному зближенні, де $\Phi$ i $\Phi_{T}$ - дійсне і потрібне значення кута $\Phi$, $\Delta \Phi$ - курсова помилка наведення, $Q$ - курсовий кут, $\omega_{m}-$ кутова швидкість літака, $\varphi_{0}-$ кут огляду бортової радіолокаційної станції, $V_{\Pi}$ - швидкість винищувача. Вісь $X$ протилежна напряму вектору швидкості цілі $\vec{V}_{L}$, вісь $Z$ перпендикулярна до неї.

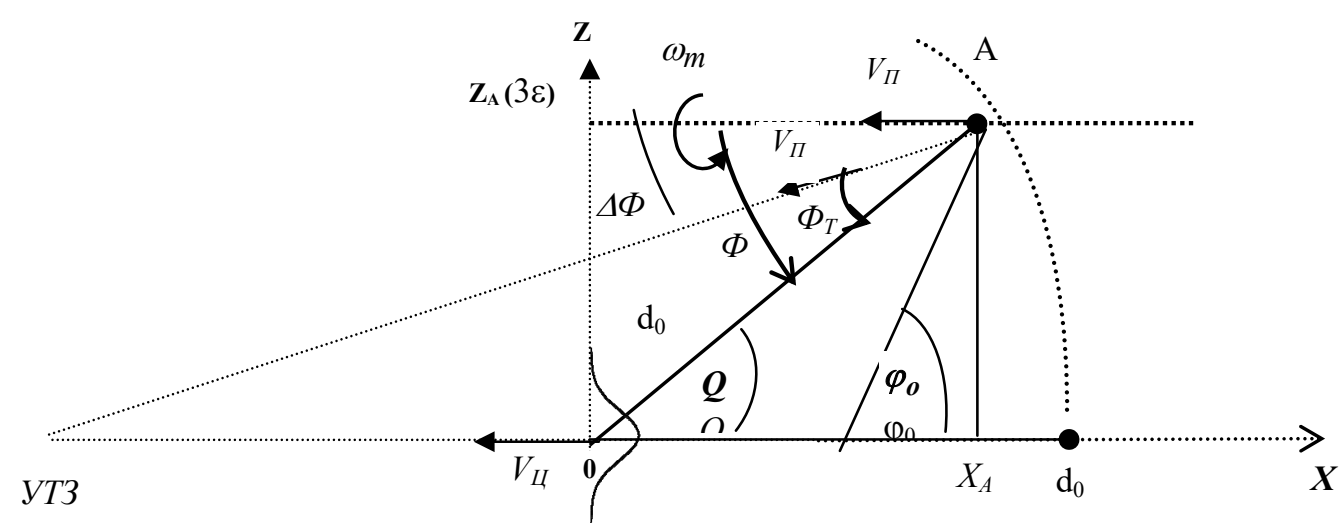

Рис. 1. Схема виникнення помилок наведення винищувача на ціль. Джерело: розроблено авторами.

При паралельному зближенні $V_{\Pi} \sin \Phi_{T}=V_{Ц} \sin Q, \quad$ закон зміни кутової швидкості винищувача $\omega_{m}=g \frac{\sqrt{n_{y}^{2}-1}}{V_{\Pi}}$. Помічаючи, що $\Phi=\Phi_{T}+\Delta \Phi$ (рис.1), диференційні рівняння траєкторії руху винищувача відносно цілі мають вигляд [5, с. 344]:

$$
\begin{gathered}
\dot{\Delta} \Phi=\frac{V_{\Pi} \cos \Phi_{T} \Delta \Phi-V_{Ц} \cos Q}{D} \Delta \Phi-\omega_{m} ; \\
\dot{Q}=\frac{V_{\Pi} \cos \Phi_{T}}{D} \Delta \Phi \\
\dot{D}=-\left(V_{\Pi} \cos \Phi_{T}-V_{\Pi} \sin \Phi_{T} \Delta \Phi-V_{Ц} \cos Q\right)
\end{gathered}
$$


Вважаючи $\Delta \Phi$ малим, знехтуємо в (1) членом $V_{\Pi} \sin \Phi_{T} \Delta \Phi . \quad \dot{D}$ будемо вважати приблизно постійним і рівним середній швидкості зближення винищувача і цілі: $\dot{D}=\bar{V}_{0}=-V_{\Pi} \cos \Phi_{T}+V_{Ц} \cos Q$.

Тоді $D=d_{0}-\bar{V}_{0} t$, де $d_{0}-$ дальність на початку усунення помилки $\Delta \Phi[5$, с. 344$]$.

В початковий момент часу помилка наведення прийняла значення $\Delta \Phi$ по абсолютній величині більша тієї, що потрібна для виконання стрільби $\Delta \Phi^{*}$ (врахування “промаху” ракети: для поразки цілі достатньо попадання ракети в коло радіуса $\Delta r)$.

Поточне лінійне значення “промаху” ракети $\Delta R$ дорівнює [5, с. 345]

$$
\Delta R=d_{0}\left(\Delta \Phi_{0}-\omega_{m} t+\omega_{m} \frac{\overline{V_{0}}}{d_{0}} \frac{t^{2}}{2}\right)
$$

де $t$ - поточний час. Якщо задати "промах" рівним його допустимому значенню $\Delta r{ }^{*}$ в момент $t_{k}=\frac{d_{0}-d_{\min } p r}{\overline{V_{0}}}$, коли відстань до цілі дорівнює мінімальному значенню $d_{\min p r}$, отримаємо значення допустимої помилки наведення $\Delta \Phi^{*}$ в початковий момент часу [5, с. 345$]$ :

$$
\Delta \Phi^{*}=\frac{\Delta r^{*}}{d_{0}}+\frac{\omega_{m}\left(d_{0}^{2}-d_{\min p r}^{2}\right)}{2 \overline{V_{0}} d_{0}} .
$$

Розглянемо задачу розрахунку ймовірності атаки малопомітної цілі з першого заходу методом паралельного зближення за допомогою методу статистичних випробувань.

Винищувач в результаті наземного наведення виводиться зі швидкістю $V_{\Pi}$ на дальності $d_{0}{ }_{3}$ деякою початковою курсовою помилкою $\Delta \Phi$ в розрахункову точку $A \quad 3$ координатами $\left(\sqrt{d_{0}^{2}-(3 \varepsilon)^{2}} ; 3 \varepsilon\right)$, де координата $z$ розподілена за нормальним законом; $d_{0}=R_{0}\left[\frac{\sigma_{t}}{\sigma_{0}}\right]^{\frac{1}{4}}, \quad$ де $R_{0}$ - дальність виявлення типової цілі за технічними умовами на дану бортову радіолокаційну станцію (БРЛС) для заданих параметрів БРЛС;

$\sigma_{t}$ - ефективна площа розсіювання ЛА для відповідного кутового положення діаграми спрямованості антени бортової РЛС;

$$
\sigma_{0} \text { - ефективна площа розсіювання типової }
$$
цілі;

$$
\varepsilon \text { - середньоквадратичне відхилення виміру }
$$
координат;

$$
d_{0}-\text { дальність виявлення цілі БРЛС }
$$

винищувача в залежності від ефективної площі розсіювання (ЕПР) $\sigma$.

При заданому методі наведення характеристики малої помітності літака враховуються в певних діапазонах ракурсів опромінення (рис. 2).

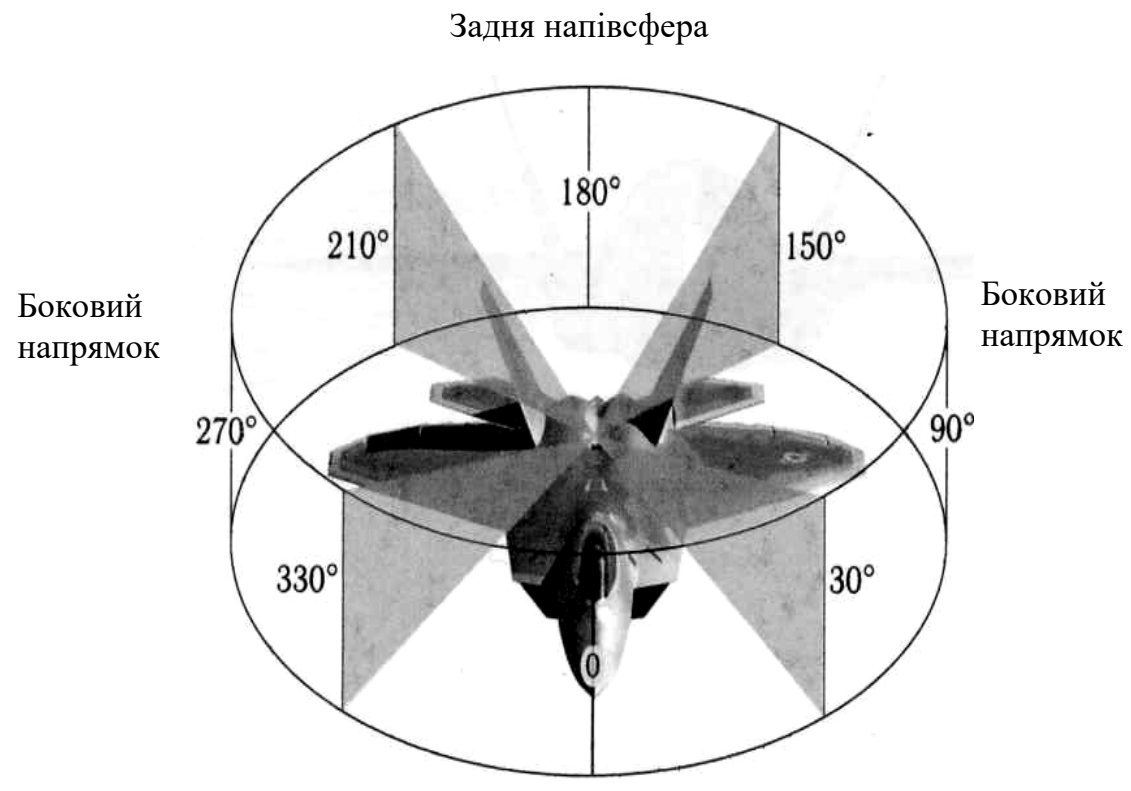

Передня напівсфера

Рис. 2. Характерні напрямки спостереження для ЛА. 
Джерело: [6, с.174].

На рис. 3 приведені графіки ЕПР зовнішньої поверхні винищувачів 5-го покоління F-22 "Raptor", F-35 "Ligthning" i модернізованого винищувача четвертого покоління F-18 “Super Hornet”в залежності від ракурсу опромінення. Розрахунки ЕПР виконувались в горизонтальній площині для випадку моностатичної локації при довжині хвилі 3,2 см (більшість сучасних радіолокаційних станцій $\epsilon$ однопозиційними, що діють в сантиметровому діапазоні хвиль) [6, с. 182, 183].

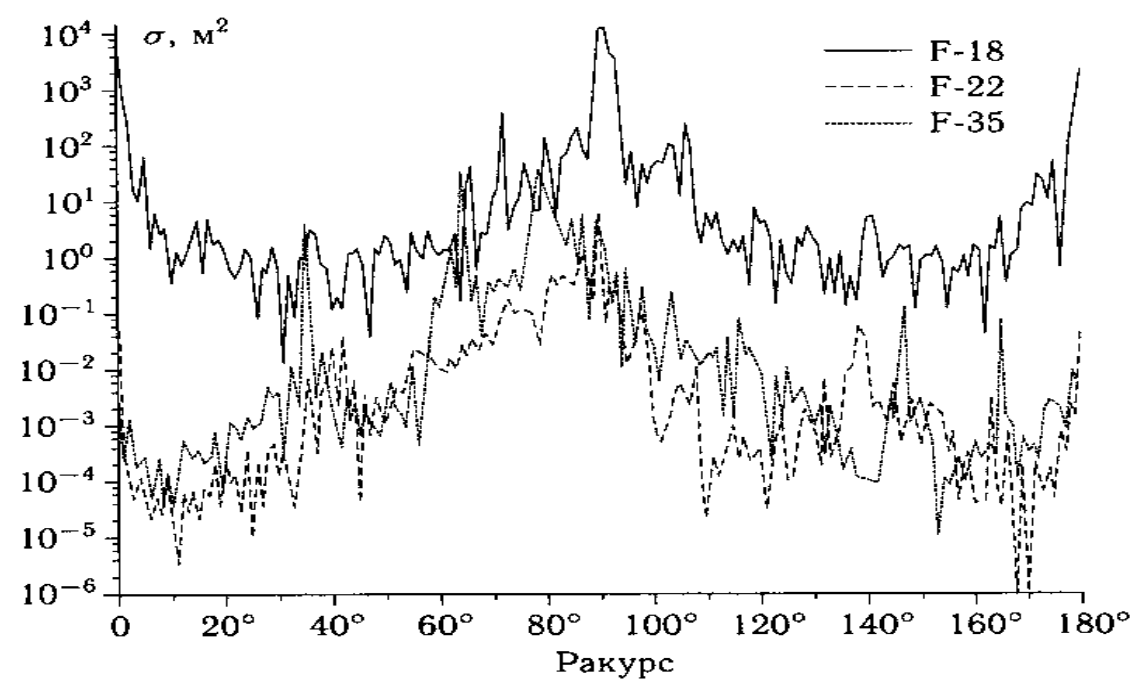

Рис. 3. ЕПР планерів сучасних закордонних винищувачів при довжині хвилі 3,2 см. Джерело: [6, с. 183].

Найбільш суттєвий вклад в ЕПР літака F-18 "Super Hornet" в діапазоні кутів $0 . . .70^{\circ}$ вносить повітрозабірник двигуна. В діапазоні бокових ракурсів опромінення $70 \ldots 110^{\circ}$ основними відбиваючими елементами $\epsilon$ поверхні вертикального оперення i бокові поверхні фюзеляжу. На ракурсах $110 \ldots 180^{\circ}$ основним відбиваючим елементом $\epsilon$ сопло двигуна. Озброєння на F-18 "Super Hornet" знаходиться на зовнішніх підвісках, які достатньо помітно відбивають опромінення радіолокаційної станції.

Реалізовані на F-22 і F-35 компоновки приводять до появи на радарі декількох відносно високих, але вузьких “піків", які важко виявити і відстежити (в подальших розрахунках знехтуємо значеннями “піків"), а величини ЕПР на діаграмі опромінення між цими “піками" малі [6, с. 183].

В якості цілі розглядається винищувач F-22. На ціль послідовно здійснюють атаку літаки F-22, F-35, F-18. Розрахунки проводились для ракурсів опромінення $70 \ldots 110^{\circ}$.

Для оцінки ймовірності бортового наведення в даній задачі застосовується метод статистичних випробувань [7, с. 409...440].

Координата $z$ точки А розподілена за нормальним законом, в початковий момент наведення кут $\Phi$ між вектором швидкості винищувача $\mathrm{i}$ напрямом на ціль дорівнює курсовому куту $Q$ і розраховується за формулою $\Phi=Q=\operatorname{arctg}\left(\frac{Z_{A}}{X_{A}}\right)$, в процесі усунення початкової помилки наведення $\Delta \Phi$ винищувач виконує як обертальний, так і поступальний рух відносно цілі, потрібне значення кута $\Phi_{T}=\arcsin \left(\sin (\Phi) \frac{V_{L}}{V_{\Pi}}\right)$, $\Delta \Phi=\Phi-\Phi_{T}$, мінімальна допустима дальність стрільби $d_{\min } p r$ визначається виразом

$$
d_{\min p r}=d_{\min }+\bar{V}_{0} \cdot t_{t s}+\bar{V}_{0} \cdot(m-1) \cdot t_{p u c k},
$$

де мінімальна дальність пуску ракети $d_{\min }=10^{3} \mathrm{~m} ; t_{t s}-$ час видачі цілевказання головки самонаведення ракети (ГСН); кількість застосовуваних ракет $m=2$; інтервал часу між пусками ракет $t_{\text {puck }}=2 \mathrm{c}$.

Вхідні дані для розрахунку імовірності бортового наведення винищувачів: нормальне перевантаження винищувачів $n_{y}=9$; величина допустимого промаху ракети $\Delta r^{*}=5 \mathrm{M}$; середньоквадратичне відхилення виміру координат $\varepsilon=1500$ м; ЕПР винищувача $\mathrm{F}-22$ в діапазоні кутів $70 \ldots 110^{\circ}$ вказані на рис. 3 і в таблиці 1 , решта даних і результати розрахунків $W$ наведені в таблиці 1. 
Таблиця 1

Результати розрахунків бортового наведення винищувачів

\begin{tabular}{|c|c|c|c|c|c|c|c|}
\hline & $\begin{array}{l}V_{\text {L } \max }, \\
M / C\end{array}$ & $\begin{array}{l}V_{\Pi \max }, \\
\mathcal{M} / \mathrm{C}\end{array}$ & $\begin{array}{c}\varphi_{0}{ }^{*} \\
\text { гpad }\end{array}$ & $\begin{array}{l}\mathrm{t}_{\mathrm{ts}} \\
\mathrm{c}\end{array}$ & $\begin{array}{c}\text { Дальність } \\
\text { виявлення иілі } \\
\text { БРЛС } \\
\text { переднього } \\
\text { обзору / ЕПР*, } \\
\kappa \mathrm{M} / \mathrm{M}^{2}\end{array}$ & $\begin{array}{c}\text { ЕПР иілі, } \\
M^{2}\end{array}$ & $\begin{array}{c}\text { Iмовірність } \\
\text { бортового } \\
\text { наведення } W\end{array}$ \\
\hline F-22 & \multirow{3}{*}{670} & 670 & \pm 60 & $4 . .6$ & $210 / 1$ & \multirow{3}{*}{$\begin{array}{l}0.032 \ldots 0.0 \\
1\end{array}$} & 0,504 \\
\hline F-35 & & 722 & \pm 120 & $4 . .6$ & $155 / 1$ & & 0,65 \\
\hline F-18 & & 527 & \pm 60 & $4 . .6$ & $155 / 1$ & & 0,11 \\
\hline
\end{tabular}

Джерело: розроблено авторами.

Примітка. Дані, позначені *, наведені в [2, с. 67, 68].

Варійовані фактори:

статистично рівномірно розподілені: швидкість винищувачів $(0,55 \ldots 0,85) V_{\Pi \max }$; швидкість цілі $(0,55 \ldots 0,85) V_{Ц \text { max }}$; час видачі цілевказання ГСН $-t_{t s}$; $\sigma-$ ЕПР при заданих ракурсах опромінення (рис.3).

За нормальним законом розподілення: координата $\mathrm{z}$ при виході винищувача в точку виявлення цілі.

Зрив атаки цілі винищувачем виникає в разі, якщо:

в момент захвата цілі БРЛС курсовий кут винищувача більше кута зони огляду бортової радіолокаційної станції - $Q>\varphi_{o}$;

відносна швидкість зближення винищувача і цілі більше нуля $-\bar{V}_{0} \geq 0(\dot{D} \geq 0)$;

кутова помилка наведення в початковий момент

часу $\Delta \Phi$ перевищує критичне значення $\Delta \Phi^{*}$ (з урахуванням допустимого лінійного “промаху” $\Delta r^{*}$ ), тобто $\Delta \Phi>\Delta \Phi^{*}$;

допустима дальність стрільби $d_{\min } p r$ більша за дальність $d_{0}$ виявлення цілі на початку усунення помилки $\Delta \Phi$.

\section{Висновки}

Невелика ймовірність бортового наведення винищувача $\mathrm{F}-18$ на ціль $(W=0,11)$ обумовлена, в основному, більшою швидкістю F-22 в порівнянні 3 F-18 і невеликою дальністю виявлення цілі. Більша ймовірність атаки цілі винищувачем $\mathrm{F}-35(\mathrm{~W}=0,65)$, ніж ймовірність наведення винищувача F-22 на літак F-22 $(0,504)$ пояснюється, по-перше, більшим кутом огляду бортової радіолокаційної станції літака F-35, по-друге, більшою швидкістю літака F-35. Отримані дані $є$ порівняльними і застосовуються при виборі раціонального варіанта багатофункціонального винищувача.

\section{Список літератури}

1. Тараненко В.В., Коцуренко Ю.В. Технічний обрис перспективного тактичного багатофункціонального літака // 3б. наук. праць. - К. ДНДІА, 2020.- Вип. № 16(23). - С. 22-28.

2. Системы управления вооружением истребителей. Основы интеллекта многофункционального самолета. Под ред. академика РАН Е.А. Федосова. - М.: Машиностроение, 2005. - 400 с.

3. Авиационные системы радиоуправления. Том 2. Радиоэлектронные системы самонаведения. Под ред. А.И. Канащенкова и В.И. Меркулова. - М.: Радиотехника, 2003. - 317 с.

4. Дуров В.Р. Боевое применение и боевая эффективность истребителей-перехватчиков. - М.: Военное издательство Министерства оборони СССР, 1972. - 280 с.

5. Мильграм Ю.Г., Попов И.С. Боевая эффективность авиационной техники и исследование операций. - М.: Издание ВВИА им. проф. Н.Е. Жуковского, 1970. - 500 с.

6. Вождаев В.В., Теперин Л.Л. Характеристики радиолокационной заметности летательных аппаратов. - М.: Физматлит, 2018. - 292 с.

7. Вентцель Е.С. Введение в исследование операций. - М.: Советское радио, 1972. - 551с.

Надійшла до редколегії 28.11.2021

Схвалена до друку 18.12.2021

\section{Відомості про авторів:}

\section{Хатунцева Зоя Вікторівна}

науковий співробітник

Державного науково-дослідного інституту авіації,

Київ, Україна

\section{Information about the authors:}

\section{Zoya Khatuntseva}

Researcher Associate

of State Research Institute of Aviation,

Kyiv, Ukraine 
https://orcid.org/0000-0002-2686-0426

\section{Маракулін Олександр Ювенальович}

старший науковий співробітник

Державного науково-дослідного інституту авіації, Київ, Україна

https://orcid.org/0000-0002-3941-8557 https://orcid.org/0000-0002-2686-0426

\section{Oleksandr Marakulin}

Senior Researcher

of State Research Institute of Aviation, Kyiv, Ukraine https://orcid.org/0000-0002-3941-8557

\title{
SIMULATION MODEL FOR CALCULATING THE PROBABILITY OF AIRBORNE GUIDANCE ON A PURPOSE WITH THE APPLICATION OF THE METHOD OF AIMING TO A FIRST POINT OF MEETING
}

\author{
Z. Khatuntseva, O. Marakulin
}

Leading world states are re-equipping their aircraft fleet with multifunctional aircraft, modernizing aircraft in service, developing and purchasing a new generation of guided aircraft weapons. The main features of such aircraft are: reduction of unmasking signs of their use in all wavelength ranges (radar, infrared, ultraviolet, visible, acoustic); ensuring great maneuverability by equipping engines with thrust vector deflection systems and using a ratchet aerodynamic scheme; ensuring a significant combat radius of action; increasing the efficiency of integrated on-board radio-electronic equipment, namely: full situational awareness (tactical, navigation, radio-electronic situation, technical condition of on-board systems); the ability to select and group targets by priority of threats, automatic detection and suppression of enemy radio-electronic means; automatic control of the radiation modes of onboard facilities in order to ensure low visibility of the aircraft; expansion of the range of application of high-precision aircraft weapons for various purposes.

In Ukraine, measures to modernize military aviation equipment and extend its resources and service life fundamentally do not ensure the preservation of military aviation in the future, but only temporarily prevent a reduction in the number and decrease in capabilities when solving problems by existing aviation groupings. When choosing a rational version of a multifunctional fighter, such efficiency criteria should be taken into account as a tactical advantage in air combat (including the presence of Stealth technologies, which are an obligatory element of fifth generation combat aircraft, the possibility of simultaneous firing of several targets), the likelihood of being hit by high-precision strikes against ground targets (including the simultaneous shelling of several targets), cost and resource indicators. The effectiveness of an attack on air targets by a fighter is to a decisive extent determined by the formation of a guidance method on board. Of the target guidance methods used in the onboard systems of fighters when using medium / long-range missiles, one can single out such as the attack curve, parallel approach, the combined homing method (combines the positive qualities of direct approach methods and the attack curve), the biased zone guidance method start-up, etc. The article provides a model for calculating the probability of airborne guidance to an unobtrusive target by the method of parallel approach. An important feature of this method is the practical straightness of the trajectory of the fighter when aiming at a non-maneuvering target. This is the implementation of the maximum range of action of the electronic control system with the minimum consumption of energy and guidance time. As a result of ground guidance, the fighter is brought out to a certain point with coordinates $A(d 0 \pm 3 e,+3 e)$ with an angular error $\Delta \Phi$, where $e$ is the standard deviation of the normal distribution, the $x$-axis coincides with the target's velocity vector. $d 0$ is calculated as a function of the effective dispersion area of the target according to the technical specifications for the onboard radar station of the fighter. In the process of eliminating the initial guidance error $\Delta \Phi$, the fighter performs both circular and sequential movement relative to the target. The effective areas of dispersion of modern foreign fighters F-18, F22, F-35, depending on the angle of irradiation, are given. In the given model, the indicated fighters are sequentially guided to the target (F-22) in the range of lateral views of irradiation 70-110 angles of exposure. Disruption of a target's attack occurs if: - at the moment the target is captured by an onboard radar station, the fighter's heading angle is greater than the viewing area angle of the onboard radar station; - the relative speed of convergence between the fighter and the target is greater than zero; - the angular guidance error at the initial moment of time $\Delta \Phi$ exceeds the critical value $\Delta \Phi^{*}$ (taking into account the permissible linear miss $\Delta r$ ).

Keywords: method of parallel guidance, biased meeting point, effective scattering area, foreshortening of irradiation. 